\title{
The price sensitivity of cigarette consumption in Bangladesh: evidence from the International Tobacco Control (ITC) Bangladesh Wave 1 (2009) and Wave 2 (2010) Surveys
}

\author{
Nigar Nargis, ${ }^{1}$ Ummul H Ruthbah, ${ }^{1}$ A K M Ghulam Hussain, ${ }^{1}$ Geoffrey T Fong, ${ }^{2,3}$ \\ Iftekharul Huq, ${ }^{4,5}$ S M Ashiquzzaman ${ }^{1}$
}

- Additional material is published online only. To view please visit the journal online (http://dx.doi.org/10.1136/ tobaccocontrol-2012-050835).

1 Department of Economics, University of Dhaka, Dhaka, Bangladesh

${ }^{2}$ Department of Psychology, University of Waterloo,

Waterloo, Ontario, Canada ${ }^{3}$ Ontario Institute of Cancer Research, Toronto, Ontario, Canada

${ }^{4}$ Department of Economics, East West University, Dhaka, Bangladesh

${ }^{5}$ Concordia University, Canada

Correspondence to Dr Nigar Nargis, Department of Economics, University of Dhaka, Dhaka 1000 Bangladesh;

nigar_nargis@econdu.ac.bd

Received 12 October 2012 Revised 1 August 2013 Accepted 5 September 2013 Published Online First 8 October 2013
To cite: Nargis $\mathrm{N}$ Ruthbah UH, Hussain AKMG, et al. Tob Control 2014;23:i39-i47.

\begin{abstract}
Background In Bangladesh, the average excise tax on cigarettes accounted for just 38\% of the average retail price of cigarettes in 2009, and $45 \%$ in 2010. Both these rates are well below the WHO recommended share of $70 \%$ of the retail price at a minimum. There is thus ample room for raising taxes on cigarettes in Bangladesh.

The objective of the present work was therefore to estimate the price elasticity of demand for cigarettes and the effect of tax increases on the consumption of cigarettes and on tax revenue in Bangladesh.

Methods Based on data from Wave 1 (2009) and Wave 2 (2010) of the International Tobacco Control Bangladesh Survey, we estimated the overall impact of a price change on cigarette demand using a two-part model. The total price elasticity of cigarettes was measured by the sum of the elasticity of smoking prevalence and the elasticity of average daily consumption conditional on smoking participation. The price elasticity estimates were used in a simulation model to predict changes in cigarette consumption and tax revenue from tax and price increases.

Results The total price elasticity of demand for cigarettes was estimated at -0.49 . The elasticity of smoking prevalence accounted for $59 \%$ of the total price elasticity. The price elasticity of cigarette consumption is higher for people belonging to lower socioeconomic status. Increases in taxes would result in a significant reduction in cigarette consumption while increasing tax revenue.
\end{abstract}

Conclusions Raising cigarette prices through increased taxation could lead to a win-win-win situation in Bangladesh: it would reduce cigarette consumption, increase tobacco tax revenue and potentially decrease socioeconomic inequities.

\section{INTRODUCTION}

Tobacco use is a leading cause of death and disability around the world. Currently, there are 41.1 million people who use tobacco in Bangladesh, including 20.9 million people who smoke. ${ }^{1}$ Although an estimated 57000 people already die each year from tobacco use, ${ }^{2}$ this number will climb considerably in the near future. The level of tobacco consumption has been moved even higher in Bangladesh by a bottom-heavy demographic structure (one-third of users are aged below 15 years), ${ }^{3}$ widespread illiteracy and poverty $31.5 \%$ of the total population lives below the poverty line). ${ }^{4}$ By any standards, therefore, tobacco use represents a critical threat to the health and welfare of the Bangladeshi people and strong action must be taken to avert this present and everdeepening threat.

Bangladesh has a history of commitment to tobacco control. It was the first country to sign the WHO Framework Convention on Tobacco Control (FCTC) and among the first 40 countries to become a Party to the FCTC. In 2005, Bangladesh enacted the Tobacco Control Act (TCA), with the corresponding regulations being implemented in 2006 . However, recent evidence from two nationally representative surveys conducted in 2009-the Global Adult Tobacco Survey (GATS) ${ }^{5}$ and the International Tobacco Control (ITC) Bangladesh Survey ${ }^{1}$-have found that despite the enactment of the TCA, Bangladesh experienced an alarming increase in tobacco consumption from 2004 to 2009.

In part, the role of the TCA in failing to reduce tobacco consumption and prevalence in Bangladesh may be due to low levels of enforcement of non-tax measures of the TCA, such as the advertising ban and smoke-free public places, and relatively low levels of implementation of warning labels (which, in accordance with the more recent Article 11 Guidelines, should include graphic images rather than the current text-only warnings). However, increases in tobacco excise taxes that increase prices have been proven to result in a decline in overall tobacco use. ${ }^{6}$ In this paper, we describe findings from the recent ITC Surveys (2009 and 2010) in Bangladesh that provide evidence in support of the potential effectiveness of increasing excise tax on cigarettes in reducing cigarette consumption in Bangladesh.

We estimated the price and income elasticity of demand for cigarettes in order to examine the effect of cigarette tax and price increases on: (1) an individual's decisions to smoke (ie, smoking prevalence); and (2) the number of cigarettes consumed per day by smokers (ie, smoking intensity). With these results, we estimated the impact of increases in cigarette taxes in Bangladesh.

Existing studies on the price responsiveness of cigarette demand in Bangladesh are very few in number. Using time series data from 1983 to 1999, Ali et al estimated statistically insignificant price elasticity of -0.27 and statistically significant income elasticity of 0.62 for cigarettes. $^{7}$ Similarly, Guindon et al used time series data from 1970 to 2000 and did not find 
any statistically significant impact of price change on cigarette demand. ${ }^{8}$ A more recent study by Barkat $e t$ al used time series data from 1984 to 2004 to obtain statistically significant negative price elasticity and positive income elasticity of demand for cigarettes in Bangladesh. ${ }^{9}$ These studies are limited by a lack of individual-level data capturing the cross-sectional variation in the factors affecting cigarette demand, as they control for only price and income in estimation and leave out other determinants of cigarette demand. Moreover, these studies are unable to distinguish between the price effects on smoking prevalence and smoking intensity. The present paper offers significant improvement in the data and method of estimating the effect of tax and price increase on cigarette consumption in Bangladesh. The preliminary results of this study were published as working papers of the University of Waterloo, Canada. ${ }^{10} 11$

\section{DATA}

The ITC Bangladesh Project was created in 2008 to evaluate the impact of tobacco control legislation in Bangladesh. The ITC Bangladesh Survey is a face-to-face survey conducted by trained interviewers from the Bureau of Economic Research at the University of Dhaka, Bangladesh, in collaboration with the ITC Project team at the University of Waterloo in Canada.

The analysis in this paper is based on data collected in Wave 1 and Wave 2 of the survey, conducted in 2009 and 2010, respectively. The Wave 1 Survey consisted of a nationally representative probability sample of 2510 adult cigarette and bidi smokers and 2116 adult non-smokers aged 15 years and older selected through a multistage cluster sampling design (sampling with probability proportional to population size at the levels of administrative units such as district, upazila/thana and village/ ward). These respondents form a cohort. They were contacted again to answer follow-up surveys in 2010 with an attrition rate of $8.3 \%$.

The smokers were oversampled for the purpose of generating a sufficiently large sample size of smokers. For the present analysis, we have limited the sample to cigarette smokers and nonsmokers and excluded the bidi smokers. Thus, the final full sample size of pooled observations of cigarette smokers and non-smokers was 8507 and of cigarette smokers was 3652 .

\section{BANGLADESH HAS AMPLE ROOM TO RAISE CIGARETTE TAX}

The current cigarette tax in Bangladesh is composed of 2 components collected at the producer level: a value added tax (VAT)
Table 2 2009-2010 Cigarette price, excise tax, VAT and consumption

\begin{tabular}{lll}
\hline Details & 2009 & $\mathbf{2 0 1 0}$ \\
\hline Average cigarette price (2009 Taka per pack of 10) & 17.4 & 19.3 \\
Average excise tax rate (\% of retail price) & 37.9 & 45.1 \\
VAT (\% of retail price) & 15.0 & 15.0 \\
Average number of cigarettes smoked per day & 10.2 & 10.5 \\
\hline
\end{tabular}

NB: 2010 prices are discounted by $8 \%$ to adjust for inflation during 2009-2010. Source: ITC Bangladesh Survey, 2009, 2010.

ITC, International Tobacco Control; VAT, value added tax.

of $15 \%$ of retail price and an excise tax, which is a supplementary duty (SD) imposed as a percentage of the retail price of cigarettes, that varies at different price ranges of cigarette packs of 10 sticks. Between 2009 and 2010, the price bands for the four tiers of cigarette prices were increased and the SD for each tier was raised by 1 percentage point (see table 1 ). The ranges of price bands are, however, not continuous. The gaps between successive tiers are shown in the row under each tier with corresponding percentage of smokers who reported prices in that range. In order to calculate the average $\mathrm{SD}$, we imputed the tax rate for each price tier to the price gap above that tier up to the lower limit of the next higher tier, in view of the fact that larger percentage of the price reported by smokers falls in the gap above the designated price tier (see last column of table 1). The existence of gaps between price tiers is a definite advantage for the producers because they pay the tax rate corresponding to the lower tier until the retail price reaches the upper tier, while enjoying higher prices and thus greater profit.

After weighting by the number of cigarettes smoked per day as reported by individual smokers, we find that the average SD increased from $38 \%$ of retail price in 2009 to $45 \%$ of retail price in 2010 and average real price of a pack of 10 cigarettes increased from 17.4 to 19.3 Taka in 2009 prices (see table 2). The average SD and cigarette price are driven down by the concentration of smokers in the lowest two price tiers: $79.8 \%$ in 2009 and $76.6 \%$ in 2010 .

Although the real price of cigarettes increased between 2009 and 2010, this was also a time of significant growth of $5.2 \%$ in the gross domestic product (GDP) per capita. ${ }^{12}$ During this time, the number of cigarettes smoked per day remained almost the same: 10.2 sticks per day in 2009 and 10.5 sticks per day in

Table 1 2009-2010 Cigarette taxes and distribution of smokers by price tiers (weighted by average daily cigarette consumption)

\begin{tabular}{|c|c|c|c|c|}
\hline Year of observation & Cigarette price band & Price tier (Taka/pack of 10) & Excise tax (percentage of retail price) & Percentage of cigarette smokers \\
\hline \multirow[t]{7}{*}{ Wave 1 (2009) } & Low & Tier $1: 7.25-8.75$ & 32 & 10.1 \\
\hline & & Gap: $8.75-16.25$ & & 63.6 \\
\hline & Medium & Tier 2: 16.25-17.25 & 52 & 0.0 \\
\hline & & Gap: 17.25-23.25 & & 6.1 \\
\hline & High & Tier 3: 23.25-29.25 & 55 & 5.3 \\
\hline & & Gap: 29.25-46.25 & & 12.0 \\
\hline & Premium & Tier 4: $46.25+$ & 57 & 2.8 \\
\hline \multirow[t]{7}{*}{ Wave 2 (2010) } & Low & Tier 1: 8.40-9.15 & 33 & 10.0 \\
\hline & & Gap: 9.15-18.40 & & 32.9 \\
\hline & Medium & Tier 2: $18.40-19.00$ & 53 & 1.0 \\
\hline & & Gap: 19.00-27.00 & & 32.7 \\
\hline & High & Tier 3: 27.00-32.00 & 56 & 14.7 \\
\hline & & Gap: 32.00-52.00 & & 7.6 \\
\hline & Premium & Tier 4: 52.00+ & 58 & 1.1 \\
\hline
\end{tabular}


2010 (table 2). It is likely that the negative effect of a modest price increase on inelastic cigarette demand was more than offset by a strong positive effect of income growth in Bangladesh.

The minor increase in the share of SD in cigarette price, with almost unaltered average consumption, indicates that the Bangladesh government has yet to gain control over cigarette prices and consumption. At the current rates of SD on cigarettes, the average share of SD in the purchase price of cigarettes has remained far below the WHO recommended level of $70 \% .^{13}$ Thus we find that there is ample room for increasing excise tax on cigarettes.

\section{ECONOMETRIC MODEL OF CIGARETTE DEMAND}

In order to estimate the overall impact of a price change on cigarette consumption resulting from lower smoking prevalence as well as lower smoking intensity of existing smokers, we constructed a two-part model following the method of Cragg. ${ }^{14}$ The total price elasticity of cigarettes is estimated as the sum of the elasticities of smoking prevalence and smoking intensity. Despite having cohort data, we did not use panel data techniques to estimate the effect of price on cigarette demand that would hold unobserved individual level heterogeneity constant. When we ran a sensitivity analysis using a fixed effects model, the effect of price became statistically insignificant, which is attributable to lack of sufficient variation in the price of cigarettes within observations for the same smoker over the 2 years. However, we expected significant cross-sectional variation in price by geographic area (village), source of purchase and mode/ volume of purchase (eg, pack or loose). Therefore, we undertook a pooled cross-sectional analysis of the Wave 1 and Wave 2 survey data. We took into account the within-person correlation of observations by correcting the standard errors (SEs) for repeated observations on the same individual using the cluster correction technique.

In the first step, we estimated the probability of smoking cigarettes as a function of price, demographic characteristics, indicators of socioeconomic status of individuals and rural/ urban area of residence. The regression was weighted to adjust for the over-representation of smokers in the survey; $18.9 \%$ of the population of adults are cigarette smokers, while this share is $41.8 \%$ in the sample. We estimated the smoking probability using the probit model:

$\operatorname{Pr}($ smoking cigarette $=1)$

$=\Phi\left(\beta_{0}+\beta_{1}\right.$ Price $+\beta_{2}$ Household income $+\beta_{3}$ Female

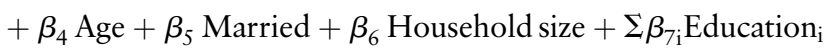

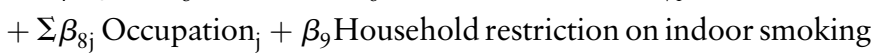

$+\beta_{10}$ Restriction onsmoking in workplace $+\beta_{11}$ Wave 2

$+\beta_{12}$ Urban area of residence $+\mathrm{u}$ )

where $\Phi($.$) is cumulative normal distribution and \mathrm{u}$ is random disturbance term.

The price elasticity of smoking participation $\left(b_{\mathrm{P}}\right)$ is obtained using the following formula:

$\mathrm{b}_{\mathrm{P}}=\phi(.) \beta_{1}$

* Average price/Population probability of cigarette smoking where $\phi($.$) is the normal density valued at the average levels of$ the explanatory variables and the estimated parameters of equation (1) and $\beta_{1}$ is estimated from equation (1). Similarly, the income elasticity of smoking participation $\left(b_{I}\right)$ is given by:

$$
\begin{aligned}
\mathrm{b}_{\mathrm{I}}= & \phi(.) \beta_{2} * \text { Average house hold income/ } \\
& \text { Population probability of cigarette smoking }
\end{aligned}
$$

In the second step, we estimated the cigarette consumption equation conditional on smoking participation from the following weighted ordinary least squares (OLS) regression:

$$
\begin{aligned}
\ln (\mathrm{C})= & \alpha_{0}+\alpha_{1} \text { Price }+\alpha_{2}{\text { Household income }+\alpha_{3} \text { Female }}+\alpha_{4} \text { Age }+\alpha_{5}{\text { Married }+\alpha_{6} \text { Household size }}+\Sigma \alpha_{7 \mathrm{i}} \text { Education }_{\mathrm{i}}+\Sigma \alpha_{8 \mathrm{j}} \text { Occupation }_{\mathrm{j}} \\
& +\alpha_{9} \text { Household restriction on indoor smoking } \\
& +\alpha_{10} \text { Restrictionon smoking in workplace } \\
& +\alpha_{11} \text { Wave } 2+\alpha_{12} \text { Urbanarea of residence }+\mathrm{e}
\end{aligned}
$$

where $\ln$ is natural logarithm and $\mathrm{e}$ is a random disturbance term. This log-linear specification of the conditional demand function is determined by using the Ramsey Regression Equation Specification Error Test (RESET). ${ }^{15}$ The coefficients of price and household income, $\alpha_{1}$ and $\alpha_{2}$, estimated from equation (2) need to be multiplied by the average price and income levels, respectively, to calculate the price and income elasticities of the conditional demand for cigarette consumption. The total price elasticity is given by $b_{P}+\alpha_{1} *$ Price and the total income elasticity is given by $b_{I}+\alpha_{2} *$ Income.

One criticism that is often raised in the context of the estimation of demand equation is that self-reported price is an endogenous variable due to the simultaneity of consumption decision and the self-reported price of consumers. ${ }^{16}$ The endogeneity of self-reported price can potentially create bias in the estimated effect of price on smoking decision of individuals and their daily cigarette consumption. In order to address this concern, the price variable was constructed by averaging the prices reported by smokers in a specific geographic area of residence (village) for each wave. This price was then assigned to smokers and non-smokers in that area.

In order to address the endogeneity problem, we also estimated a second set of equations using instrumental variable probit model for smoking participation and two-stage least squares (2SLS) model for daily consumption. In the first stage, the price was regressed on the tax variable given by the sum of the SD and the VAT rates along with other socioeconomic and demographic characteristics of individual respondents present in equations (1) and (2). The price variable predicted from the first stage regression was then used in the second stage estimation of smoking participation and daily consumption.

As the SD is ad valorem with four tiers corresponding to four price bands and the rates differ between the 2 years of the survey (table 1), we can identify the price variable in two waves with eight different SD rates. For example, if the price facing an individual was 8 Taka per pack in 2009, the value of the tax variable for that individual is the sum of the corresponding SD rate of $32 \%$ and the value added tax of $15 \%$, that is $47 \%$.

The coefficient of the tax variable in the reduced form regression for price is 75.18 , which implies that if the tax rate increases by 1 percentage point, the average price per pack of 10 cigarettes increases by 0.75 Taka (see online supplementary table A3). The statistically significant coefficient of the tax 
variable indicates that it is highly correlated with price. This tax variable was also tested as a valid instrumental for price, as we found a very large F statistic (greater than 10) in the reduced form regression for price. According to Stock and Watson, if there is one right-hand-side endogenous variable, one can use the $\mathrm{F}$ statistic from the first-stage regression to test for the significance of the instrument if the $\mathrm{F}$ statistic should be greater than $10 .^{17}$

All the equations were estimated for the tertiles of individuals stratified on the basis of the housing index representing their socioeconomic status (low, medium and high). Thus, we obtained price and income elasticity estimates for the overall population and for population subgroups by socioeconomic status.

\section{RESULTS OF ESTIMATION}

The participation equations for cigarette smoking obtained from probit and instrumental probit estimation are reported in tables 3 and 4, respectively. The conditional demand equation for daily cigarette consumption of smokers obtained from OLS and 2SLS estimation are reported in tables 5 and 6 , respectively. The tables in the Appendix present the means of the variables used in the estimation (see online supplementary table A1), the reduced form equation for price used in instrumental variable probit model (see online supplementary table A2) and the reduced form equation for price used in the 2SLS model (see online supplementary table A3).

In the instrumental probit regression, the Wald test of exogeneity of regressors was used to test for the orthogonality of the unobserved disturbances in the decision to smoke and the price equation. ${ }^{18}$ The Wald $\chi^{2}$ statistic reported in table 4 rejects the hypothesis of the exogeneity of regressors in the smoking prevalence equation, indicating that self-reported price is endogenous. Similarly, the orthogonality of the unobserved disturbances in the daily consumption of cigarettes and the price equation was tested in the 2SLS regression for the conditional demand function for all smokers. In this regression, the exogeneity of regressors was also rejected as indicated by the statistically significant robust regression $\mathrm{F}$ statistics in table 6 .

The validity of the use of the tax variable as an instrument for self-reported price is indicated by the estimates of the coefficient of the tax variable that are statistically significantly different from zero in the reduced form price equations corresponding to the instrumental probit and 2SLS regression

Table 3 Probit estimates for prevalence of cigarette smoking (dependent variable 1 if cigarette smoker, 0 if non-smoker)

\begin{tabular}{|c|c|c|c|c|}
\hline \multirow[b]{2}{*}{ Demographic } & \multicolumn{4}{|c|}{ Socioeconomic status group } \\
\hline & (1) All & (2) Low & (3) Medium & (4) High \\
\hline Cigarette price/pack (2009 Taka) & $0.00312(0.73)$ & $0.000595(0.07)$ & $-0.000291(-0.04)$ & $0.0103(1.36)$ \\
\hline Monthly household income (2009 Taka) & $0.00312(0.73)$ & $0.000595(0.07)$ & $-0.000291(-0.04)$ & $0.0103(1.36)$ \\
\hline Female & $-1.719^{* * *}(-21.86)$ & $-1.477^{* * *}(-12.13)$ & $-1.822^{* * *}(-11.69)$ & $-1.965^{* * *}(-12.92)$ \\
\hline Age & $-0.00863^{* * *}(-5.75)$ & $-0.00852^{* * *}(-3.82)$ & $-0.00783^{* *}(-2.80)$ & $-0.0111^{* * *}(-3.58)$ \\
\hline Married & $0.243^{* * *}(4.53)$ & $0.251^{* *}(2.93)$ & $0.413^{* * *}(4.21)$ & $0.155(1.49)$ \\
\hline Household size & $0.0502^{* * *}(3.55)$ & $0.0369(1.57)$ & $0.0535^{*}(1.96)$ & $0.0557^{*}(2.15)$ \\
\hline \multicolumn{5}{|l|}{ Education } \\
\hline Primary (1-5 years) & $0.177^{* * *}(3.42)$ & $0.243^{* * *}(3.46)$ & $0.148(1.60)$ & $-0.211(-1.38)$ \\
\hline Secondary (6-8 years) & $0.207^{* * *}(3.37)$ & $0.214^{*}(2.40)$ & $0.253^{*}(2.23)$ & $-0.138(-0.86)$ \\
\hline Secondary School Certificate (9-10 years) & $0.0968(1.32)$ & $0.185(1.47)$ & $0.258^{*}(1.96)$ & $-0.396^{*}(-2.41)$ \\
\hline Higher Secondary Certificate (11-12 years) & $0.259 * *(2.68)$ & $0.303(1.23)$ & $0.648^{* * *}(3.38)$ & $-0.283(-1.62)$ \\
\hline Bachelor's (14-16 years) & $0.368 * *(3.15)$ & $1.888^{* * *}(5.97)$ & $0.731^{* *}(2.64)$ & $-0.164(-0.92)$ \\
\hline Master's (15-17 years) & $0.404^{*}(2.25)$ & $-0.119(-0.18)$ & - & $-0.0791(-0.33)$ \\
\hline Above Master's & $-0.0255(-0.05)$ & - & - & $-0.932(-1.83)$ \\
\hline \multicolumn{5}{|l|}{ Occupation } \\
\hline Tenant farmer & $0.144(1.60)$ & $0.0244(0.17)$ & $0.267(1.67)$ & $0.426^{*}(2.17)$ \\
\hline Self-employed in non-farm agriculture & $-0.221^{*}(-2.07)$ & $-0.165(-1.14)$ & $-0.601 * *(-2.94)$ & $0.302(0.90)$ \\
\hline Self-employed in non-agricultural activity & $0.191(1.91)$ & $0.367^{*}(2.23)$ & $0.0903(0.55)$ & $0.197(0.95)$ \\
\hline Farm wage labourer & $0.101(1.20)$ & $0.0290(0.24)$ & $0.107(0.69)$ & $0.664^{* *}(3.09)$ \\
\hline Non-farm agricultural wage labourer & $-0.176(-0.86)$ & $-0.348(-0.77)$ & $-0.394(-0.88)$ & $0.447(1.35)$ \\
\hline Non-agricultural wage labourer & $0.339^{* *}(3.08)$ & $0.385^{*}(2.22)$ & $0.230(1.18)$ & $0.699^{* *}(2.80)$ \\
\hline Professional & $-0.625^{* * *}(-4.91)$ & $-0.924^{* * *}(-3.53)$ & $-0.953^{* *}(-3.25)$ & $-0.212(-0.97)$ \\
\hline Managerial/administrative/clerking & $-0.111(-1.10)$ & $-0.281(-1.69)$ & $-0.210(-1.13)$ & $0.237(1.16)$ \\
\hline Student & $-1.054^{* * *}(-10.08)$ & $-1.449^{* * *}(-7.33)$ & $-1.383^{* * *}(-6.44)$ & $-0.586^{* *}(-2.93)$ \\
\hline Unemployed & $0.0884(1.09)$ & $0.0471(0.39)$ & $-0.0234(-0.16)$ & $0.445^{*}(2.42)$ \\
\hline Homemaker & $-0.775^{* * *}(-6.31)$ & $-0.702^{* * *}(-3.74)$ & $-0.826^{* * *}(-3.91)$ & $-0.914^{* * *}(-3.54)$ \\
\hline Others & $0.196^{*}(2.51)$ & $0.320^{* *}(2.67)$ & $0.161(1.16)$ & $0.254(1.52)$ \\
\hline Indoor smoking restriction (1 yes, 0 no) & $-0.109 * *(-2.83)$ & $-0.0200(-0.35)$ & $-0.130(-1.84)$ & $-0.312^{* * *}(-3.68)$ \\
\hline Workplace smoking restriction (1 yes, 0 no) & $-0.000261(-0.00)$ & $0.237(1.72)$ & $-0.0826(-0.61)$ & $-0.122(-1.14)$ \\
\hline Urban area of residence & $0.218^{* * *}(3.82)$ & $0.193^{*}(2.06)$ & $0.188(1.87)$ & $0.208(1.70)$ \\
\hline Wave 2 & $-0.182^{* * *}(-5.14)$ & $-0.302^{* * *}(-5.04)$ & $-0.192 * *(-2.83)$ & $0.0600(0.77)$ \\
\hline Observations & 8507 & 3484 & 2540 & 2477 \\
\hline
\end{tabular}

Coefficients are marginal effects. For dummy variables, the marginal effect refers to effect of discrete change in the dummy variable from 0 to 1 . The $z$ statistics of the coefficients are in parentheses. Omitted categories include male gender, illiterate, owner farmers (occupation), the time effect of wave 1 and rural area of residence.

${ }^{*} p<0.05,{ }^{* *} p<0.01,{ }^{* * *} p<0.001$. 
Table 4 Instrumental variable probit estimates for prevalence of cigarette smoking (dependent variable 1 if cigarette smoker, 0 if non-smoker)

\begin{tabular}{|c|c|c|c|c|}
\hline \multirow[b]{2}{*}{ Demographic } & \multicolumn{4}{|c|}{ Socioeconomic status group } \\
\hline & (1) All & (2) Low & (3) Medium & (4) High \\
\hline Predicted price of cigarette/pack (2009 Taka) & $-0.0217^{* * *}(-4.83)$ & $-0.0384^{* *}(-3.24)$ & $-0.0252^{* *}(-3.15)$ & $-0.0104(-1.29)$ \\
\hline Monthly household income (2009 Taka) & $0.0000192^{* * *}(4.14)$ & $0.0000252^{* *}(2.76)$ & $0.0000165(1.85)$ & $0.0000116(1.60)$ \\
\hline Female & $-1.680^{* * *}(-21.63)$ & $-1.488^{* * *}(-12.32)$ & $-1.783^{* * *}(-11.65)$ & $-1.887^{* * *}(-12.57)$ \\
\hline Age & $-0.00823^{* * *}(-5.61)$ & $-0.00760^{* * *}(-3.41)$ & $-0.00811^{* *}(-2.96)$ & $-0.00947^{* *}(-3.19)$ \\
\hline Married & $0.222^{* * *}(4.16)$ & $0.235^{* *}(2.72)$ & $0.388^{* * *}(4.00)$ & $0.111(1.10)$ \\
\hline Household size & $0.0474^{* * *}(3.38)$ & $0.0340(1.46)$ & $0.0516(1.93)$ & $0.0554^{*}(2.19)$ \\
\hline \multicolumn{5}{|l|}{ Education } \\
\hline Primary (1-5 years) & $0.187^{* * *}(3.71)$ & $0.269^{* * *}(3.83)$ & $0.158(1.74)$ & $-0.220(-1.50)$ \\
\hline Secondary (6-8 years) & $0.236^{* * *}(3.89)$ & $0.253^{* *}(2.85)$ & $0.283^{*}(2.51)$ & $-0.123(-0.80)$ \\
\hline SSC (9-10 years) & $0.142(1.94)$ & $0.231(1.82)$ & $0.280 *(2.13)$ & $-0.365^{*}(-2.28)$ \\
\hline Higher Secondary Certificate (11-12 years) & $0.372^{* * *}(3.81)$ & $0.422(1.73)$ & $0.727^{* * *}(3.66)$ & $-0.209(-1.22)$ \\
\hline Bachelor's ( $14-16$ years) & $0.538^{* * *}(4.43)$ & $1.865^{* * *}(5.78)$ & $0.848^{* *}(2.98)$ & $-0.0831(-0.46)$ \\
\hline Master's (15-17 years) & $0.701^{* * *}(3.54)$ & $0.0194(0.03)$ & - & $0.108(0.43)$ \\
\hline Above master's & $0.128(0.26)$ & - & - & $-0.784(-1.63)$ \\
\hline \multicolumn{5}{|l|}{ Occupation } \\
\hline Tenant farmer & $0.154(1.73)$ & $0.0352(0.25)$ & $0.217(1.38)$ & $0.458^{*}(2.43)$ \\
\hline Self-employed in non-farm agriculture & $-0.240^{*}(-2.30)$ & $-0.198(-1.38)$ & $-0.634^{* *}(-3.13)$ & $0.321(1.02)$ \\
\hline Self-employed in non-agricultural activity & $0.194^{*}(1.96)$ & $0.361 *(2.18)$ & $0.0802(0.49)$ & $0.253(1.28)$ \\
\hline Farm wage labourer & $0.0859(1.04)$ & $0.0117(0.10)$ & $0.0674(0.44)$ & $0.668^{* *}(3.24)$ \\
\hline Non-farm agricultural wage labourer & $-0.166(-0.78)$ & $-0.210(-0.48)$ & $-0.453(-1.01)$ & $0.461(1.39)$ \\
\hline Non-agricultural wage labourer & $0.342^{* *}(3.15)$ & $0.371 *(2.12)$ & $0.197(1.03)$ & $0.801^{* *}(3.28)$ \\
\hline Professional & $-0.625^{* * *}(-4.88)$ & $-0.907^{* * *}(-3.44)$ & $-0.973^{* *}(-3.27)$ & $-0.140(-0.67)$ \\
\hline Managerial/administrative/clerking & $-0.116(-1.16)$ & $-0.322(-1.96)$ & $-0.209(-1.14)$ & $0.283(1.46)$ \\
\hline Student & $-1.036^{* * *}(-10.01)$ & $-1.403^{* * *}(-7.21)$ & $-1.394^{* * *}(-6.55)$ & $-0.538^{* *}(-2.77)$ \\
\hline Unemployed & $0.0671(0.84)$ & $0.0120(0.10)$ & $-0.0517(-0.37)$ & $0.445^{* *}(2.59)$ \\
\hline Homemaker & $-0.743^{* * *}(-6.19)$ & $-0.656^{* * *}(-3.54)$ & $-0.843^{* * *}(-4.06)$ & $-0.813^{* *}(-3.25)$ \\
\hline Others & $0.215^{* *}(2.77)$ & $0.314^{* *}(2.64)$ & $0.165(1.20)$ & $0.314(1.96)$ \\
\hline Indoor smoking restriction (1 yes, 0 no) & $-0.0912 *(-2.41)$ & $-0.0227(-0.40)$ & $-0.119(-1.70)$ & $-0.258^{* *}(-3.16)$ \\
\hline Workplace smoking restriction ( 1 yes, 0 no) & $0.0277(0.39)$ & $0.300 *(2.13)$ & $-0.0345(-0.25)$ & $-0.136(-1.29)$ \\
\hline Urban area of residence & $0.341^{* * *}(6.28)$ & $0.277^{* *}(2.90)$ & $0.264^{* *}(2.82)$ & $0.356^{* *}(3.21)$ \\
\hline Wave 2 & $-0.178^{* * *}(-5.11)$ & $-0.266^{* * *}(-4.42)$ & $-0.190^{* *}(-2.83)$ & $0.0717(0.95)$ \\
\hline Observations & 8507 & 3484 & 2540 & 2477 \\
\hline \multicolumn{5}{|l|}{ Wald test of exogeneity } \\
\hline$\chi^{2}$ & 45.88 & 19.52 & 11.87 & 32.67 \\
\hline $\mathrm{p}$ Value & 0.00 & 0.00 & 0.00 & 0.00 \\
\hline
\end{tabular}

Coefficients are marginal effects. For dummy variables, the marginal effect refers to effect of discrete change in the dummy variable from 0 to 1 . The $z$ statistics of the coefficients are in parentheses. Omitted categories include male gender, illiterate, owner farmers (occupation), the time effect of wave 1 and rural area of residence. The reduced form estimate of the price equation is reported in online appendix in table $\mathrm{A} 2$.

${ }^{*} p<0.05,{ }^{* *} p<0.01,{ }^{* * *} p<0.001$.

(reported in online supplementary tables A2 and A3, respectively). The large value of the robust $\mathrm{F}$ statistic (greater than 10) in online supplementary table A3 also shows that the tax variable is not a weak instrument for self-reported price. Therefore, we accepted the instrumental variables estimates of the coefficients of the price variable for smoking prevalence and conditional demand functions for the purpose of estimating the price elasticity of demand for cigarettes.

Given the statistical significance and negative sign of the estimates of the price coefficient and the validity of the instrument used in the instrumental variable probit and 2SLS regressions, we used the corresponding estimated coefficients of price and income to calculate the price and income elasticity at the mean price level (table 7). The total price elasticity was -0.49 for the full sample indicating that a $10 \%$ increase in the price of cigarettes is expected to lead to $4.9 \%$ reduction in cigarette consumption. Most estimates of price elasticity of cigarette demand in low-income and middle-income countries range from -0.5 to
-1.0 , while those for high-income countries tend to fall in the range of -0.25 to $-0.5{ }^{19}$ The present estimate is on the lower side of this range and lies between the short run price elasticity of -0.41 and long run price elasticity of -0.57 obtained in a previous study in Bangladesh. ${ }^{9}$ Further, we obtained the instrumental variable estimate of the total income elasticity at 0.23 (table 7), which implies that $10 \%$ increase in household income is expected to lead to $2.3 \%$ growth in cigarette consumption

\section{IMPACT OF TAX INCREASES AND CHANGES IN TAX STRUCTURE ON CIGARETTE CONSUMPTION AND REVENUE}

Using the price and income elasticity estimates for cigarette smoking prevalence and conditional cigarette demand, we simulated tax increases and different tax structures to assess the effect of those changes on overall cigarette consumption and tax revenue. The results are reported in table 8 . The baseline year was set in the fiscal year 2012-2013 with the existing fourtiered tax structure and the projection was made for 2013- 
Table 5 OLS estimates of conditional demand for cigarettes

\begin{tabular}{|c|c|c|c|c|}
\hline \multirow[b]{2}{*}{ Dependent variable, $\operatorname{Ln}$ (daily consumption) } & \multicolumn{4}{|c|}{ Socioeconomic status group } \\
\hline & (1) All & (2) Low & (3) Medium & (4) High \\
\hline Cigarette price, 2009 Taka/pack & $-0.0118^{* * *}(-4.85)$ & $-0.0276^{* * *}(-4.75)$ & $-0.00420(-0.99)$ & $-0.00602(-1.47)$ \\
\hline Monthly household income (2009 Taka) & $0.00000889 * * *(3.31)$ & $0.0000247^{* * *}(4.12)$ & $0.00000506(1.06)$ & $0.00000235(0.60)$ \\
\hline Female & $0.0140(0.12)$ & $-0.174(-1.40)$ & $0.0393(0.14)$ & $0.212(1.05)$ \\
\hline Age & $-0.00116(-1.13)$ & $-0.000754(-0.45)$ & $-0.00386^{*}(-2.43)$ & $0.000757(0.42)$ \\
\hline Married & $0.0839 * *(2.65)$ & $0.0114(0.20)$ & $0.110^{*}(2.11)$ & $0.134^{*}(2.48)$ \\
\hline Household size & $-0.00893(-1.02)$ & $-0.0231(-1.24)$ & $0.0280 *(2.14)$ & $-0.0285^{*}(-2.24)$ \\
\hline \multicolumn{5}{|l|}{ Education } \\
\hline Primary (1-5 years) & $0.0983 *(2.46)$ & $0.114(1.92)$ & $0.0636(1.11)$ & $0.0695(0.77)$ \\
\hline Secondary (6-8 years) & $0.0722(1.72)$ & $0.215^{* * *}(3.37)$ & $-0.0104(-0.16)$ & $-0.0665(-0.73)$ \\
\hline Secondary School Certificate (9-10 years) & $0.0573(1.16)$ & $0.0880(1.04)$ & $0.0310(0.42)$ & $-0.0390(-0.38)$ \\
\hline Higher Secondary Certificate (11-12 years) & $0.0108(0.19)$ & $0.0608(0.43)$ & $-0.163(-1.63)$ & $-0.0147(-0.15)$ \\
\hline Bachelor's ( $14-16$ years) & $0.0824(1.22)$ & $-0.167(-0.91)$ & $0.0347(0.25)$ & $0.0630(0.61)$ \\
\hline Master's (15-17 years) & $-0.149(-0.92)$ & $0.289(0.84)$ & $-0.307(-1.13)$ & $-0.183(-0.95)$ \\
\hline Above Master's & $0.0216(0.11)$ & $-0.150(-0.48)$ & - & $-0.0984(-0.44)$ \\
\hline \multicolumn{5}{|l|}{ Occupation } \\
\hline Tenant farmer & $0.204^{* *}(3.01)$ & $0.288^{* *}(2.61)$ & $0.187(1.76)$ & $0.173(1.15)$ \\
\hline Self-employed in non-farm agriculture & $0.170 *(2.16)$ & $0.174(1.64)$ & $0.291^{*}(2.05)$ & $0.0517(0.33)$ \\
\hline Self-employed in non-agricultural activity & $0.275^{* * *}(4.09)$ & $0.201(1.75)$ & $0.311^{* *}(3.06)$ & $0.250(1.83)$ \\
\hline Farm wage labourer & $0.177^{* *}(2.72)$ & $0.0873(0.92)$ & $0.266 * *(2.61)$ & $0.284(1.91)$ \\
\hline Non-farm agricultural wage labourer & $0.175(0.95)$ & $-0.434(-1.17)$ & $0.363(1.91)$ & $0.342(1.88)$ \\
\hline Non-agricultural wage labourer & $0.274^{* * *}(3.80)$ & $0.312^{* *}(2.95)$ & $0.378^{* * *}(3.51)$ & $0.109(0.67)$ \\
\hline Professional & $0.174(1.62)$ & $0.596^{* * *}(3.40)$ & $0.0234(0.10)$ & $0.168(1.07)$ \\
\hline Managerial/administrative/clerking & $0.236^{* *}(3.05)$ & $0.194(1.52)$ & $0.301 * *(2.62)$ & $0.107(0.68)$ \\
\hline Student & $0.0857(0.69)$ & $0.0264(0.09)$ & $0.393(1.45)$ & $-0.0420(-0.22)$ \\
\hline Unemployed & $0.260^{* * *}(4.06)$ & $0.258 * *(2.77)$ & $0.341 * *(3.28)$ & $0.172(1.21)$ \\
\hline Homemaker & $0.0948(0.68)$ & $0.0377(0.15)$ & $0.207(0.83)$ & $0.0990(0.43)$ \\
\hline Others & $0.236^{* * *}(3.92)$ & $0.251^{* *}(2.78)$ & $0.331^{* * *}(3.38)$ & $0.105(0.80)$ \\
\hline Indoor smoking restriction (1 yes, 0 no) & $-0.0405(-1.52)$ & $0.0119(0.28)$ & $-0.0547(-1.27)$ & $-0.147^{* *}(-3.17)$ \\
\hline Workplace smoking restriction (1 yes, 0 no) & $-0.0612(-1.65)$ & $0.0418(0.63)$ & $-0.0393(-0.59)$ & $-0.113^{*}(-1.97)$ \\
\hline Urban area of residence & $0.0482(1.53)$ & $0.112^{*}(2.08)$ & $-0.00815(-0.18)$ & $-0.0159(-0.25)$ \\
\hline Wave 2 & $0.0851^{* *}(2.81)$ & $0.103 *(1.98)$ & $0.0507(1.02)$ & $0.157^{*}(2.48)$ \\
\hline Observations & 3652 & 1311 & 1134 & 1207 \\
\hline Adjusted $\mathrm{R}^{2}$ & 0.030 & 0.061 & 0.042 & 0.057 \\
\hline
\end{tabular}

2014. The SD rates are higher in 2012-2013 than those prevailing in the survey years 2009 and 2010 shown in table 1.

Three alternative tax structures were simulated to assess the possible impact of tax policy changes on cigarette consumption and revenue: (1) uniform ad valorem tax at the rate of $61 \%$ of retail price of cigarettes; (2) uniform ad valorem tax at the rate of $61 \%$ of retail price of cigarettes with a specific minimum of 20 Taka (in 2012-2013 prices) per pack of 10 cigarettes; and (3) uniform specific tax of 22 Taka (in 2012-2013 prices) per pack of 10 cigarettes.

These alternatives were chosen so that the average excise tax per pack of cigarettes is comparable across the three options as shown in the first row of table 8 .

The baseline population size is 152518015 as projected for 2012 in the Bangladesh Population and Housing Census 2011 and the adult population constitutes $69 \%$ of the total population. ${ }^{3}$ The adult population size was multiplied with the cigarette smoking prevalence rate to estimate the number of cigarettes smokers in Bangladesh in 2012-2013. We projected the negative impact of the tax policy changes onto the number of adult smokers and the annual cigarette consumption using the price elasticities of smoking participation and conditional demand for cigarettes, respectively.

The annual rate of per capita GDP growth is 4.9\% in 2013, according to the projection of the IMF. ${ }^{12}$ The income elasticities of cigarette smoking participation and daily cigarette consumption were used to project the positive impact of income growth on the number of smokers and conditional demand for cigarettes, respectively. In addition, we took into account the growth in the number of adult smokers driven by population growth at the annual rate of $1.24 \%$. The price increases were adjusted for inflation at the annual rate of $8 \%$.

The net changes caused by price and income growth in the number of smokers, annual cigarette consumption and tax revenue are presented in table 8 . Overall, the annual projection reveals that cigarette consumption could be reduced and cigarette tax revenue increased significantly by the simulated changes in the tax rates and structure. The highest price increases and decreases in the number of smokers and annual cigarette consumption occur under the uniform specific tax system, while the 
Table 6 Instrumental variable 2SLS estimates of conditional demand for cigarettes

\begin{tabular}{|c|c|c|c|c|}
\hline \multirow[b]{2}{*}{ Demographic } & \multicolumn{4}{|c|}{ Socioeconomic status group } \\
\hline & (1) All & (2) Low & (3) Medium & (4) High \\
\hline In (predicted price of cigarettes, 2009 Taka/pack) & $-0.0110^{* * *}(-5.67)$ & $-0.0161 * * *(-3.69)$ & $-0.00543(-1.91)$ & $-0.00923^{* *}(-3.05)$ \\
\hline Monthly household income (2009 Taka) & $0.0000116^{* * *}(4.19)$ & $0.0000267^{* * *}(4.50)$ & $0.00000529(1.15)$ & $0.00000707(1.65)$ \\
\hline Female & $0.0193(0.16)$ & $-0.181(-1.38)$ & $0.0227(0.08)$ & $0.237(1.09)$ \\
\hline Age & $-0.00212^{*}(-2.03)$ & $-0.00175(-1.03)$ & $-0.00442 * *(-2.82)$ & $-0.000407(-0.21)$ \\
\hline Married & $0.0815^{*}(2.57)$ & $0.0132(0.24)$ & $0.108^{*}(2.09)$ & $0.134^{*}(2.45)$ \\
\hline Household size & $-0.0102(-1.17)$ & $-0.0224(-1.21)$ & $0.0286^{*}(2.25)$ & $-0.0321^{* *}(-2.59)$ \\
\hline \multicolumn{5}{|l|}{ Education } \\
\hline Primary ( $1-5$ years) & $0.0972 *(2.45)$ & $0.0991(1.67)$ & $0.0641(1.14)$ & $0.0786(0.90)$ \\
\hline Secondary (6-8 years) & $0.0949 *(2.26)$ & $0.189 * *(2.99)$ & $0.0230(0.34)$ & $-0.0387(-0.44)$ \\
\hline Secondary School Certificate (9-10 years) & $0.0889(1.81)$ & $0.103(1.24)$ & $0.0500(0.70)$ & $-0.00190(-0.02)$ \\
\hline Higher Secondary Certificate (11-12 years) & $0.0656(1.11)$ & $0.109(0.86)$ & $-0.120(-1.14)$ & $0.0345(0.35)$ \\
\hline Bachelor's (14-16 years) & $0.154^{*}(2.25)$ & $-0.0570(-0.31)$ & $0.0883(0.64)$ & $0.126(1.19)$ \\
\hline Master's (15-17 years) & $-0.0158(-0.09)$ & $0.475(1.82)$ & $-0.218(-0.75)$ & $-0.0661(-0.33)$ \\
\hline Above Master's & $0.0668(0.34)$ & $-0.106(-0.39)$ & - & $-0.0165(-0.07)$ \\
\hline \multicolumn{5}{|l|}{ Occupation } \\
\hline Tenant farmer & $0.202 * *(3.01)$ & $0.274^{*}(2.49)$ & $0.182(1.73)$ & $0.198(1.36)$ \\
\hline Self-employed in non-farm agriculture & $0.150(1.95)$ & $0.174(1.64)$ & $0.274(1.94)$ & $0.0201(0.13)$ \\
\hline Self-employed in non-agricultural activity & $0.263 * * *(3.97)$ & $0.178(1.54)$ & $0.308 * *(3.08)$ & $0.259 *(1.98)$ \\
\hline Farm wage labourer & $0.163 *(2.52)$ & $0.0624(0.65)$ & $0.261 * *(2.58)$ & $0.286^{*}(2.02)$ \\
\hline Non-farm agricultural wage labourer & $0.208(1.08)$ & $-0.462(-1.25)$ & $0.352(1.77)$ & $0.405^{*}(2.25)$ \\
\hline Non-agricultural wage labourer & $0.243 * * *(3.41)$ & $0.278^{* *}(2.64)$ & $0.364 * * *(3.45)$ & $0.0884(0.57)$ \\
\hline Professional & $0.154(1.41)$ & $0.516^{* *}(2.58)$ & $0.0301(0.13)$ & $0.153(1.01)$ \\
\hline Managerial/administrative/clerking & $0.228^{* *}(3.02)$ & $0.191(1.52)$ & $0.303^{* *}(2.73)$ & $0.121(0.80)$ \\
\hline Student & $0.0859(0.70)$ & $0.148(0.56)$ & $0.370(1.44)$ & $-0.0244(-0.13)$ \\
\hline Unemployed & $0.248^{* * *}(3.91)$ & $0.263^{* *}(2.76)$ & $0.338 * *(3.29)$ & $0.148(1.12)$ \\
\hline Homemaker & $0.0735(0.52)$ & $0.0334(0.14)$ & $0.206(0.84)$ & $0.0787(0.35)$ \\
\hline Others & $0.238 * * *(3.96)$ & $0.227^{*}(2.49)$ & $0.340 * * *(3.55)$ & $0.118(0.93)$ \\
\hline Indoor smoking restriction ( 1 yes, 0 no) & $-0.0345(-1.29)$ & $0.0242(0.57)$ & $-0.0538(-1.25)$ & $-0.134^{* *}(-2.92)$ \\
\hline Workplace smoking restriction ( 1 yes, 0 no) & $-0.0595(-1.61)$ & $0.00811(0.13)$ & $-0.0415(-0.63)$ & $-0.102(-1.80)$ \\
\hline Urban area of residence & $0.0158(0.55)$ & $0.0740(1.34)$ & $-0.0216(-0.51)$ & $-0.0162(-0.31)$ \\
\hline Wave 2 & $0.0813^{* *}(2.68)$ & $0.0975(1.89)$ & $0.0560(1.14)$ & $0.158^{*}(2.44)$ \\
\hline Observations & 3652 & 1311 & 1134 & 1207 \\
\hline Adjusted $\mathrm{R}^{2}$ & 0.022 & 0.051 & 0.046 & 0.043 \\
\hline \multicolumn{5}{|l|}{ Test of endogeneity: HO: variables are exogenous } \\
\hline Robust regression $\mathrm{F}$ & 11.73 & 2.62 & 0.53 & 5.41 \\
\hline $\mathrm{p}$ Value & 0.00 & 0.11 & 0.46 & 0.02 \\
\hline
\end{tabular}

highest revenue gain and tax share in the retail price occur under the uniform ad valorem tax system. Therefore, it appears that the revenue goal is better served with an ad valorem tax system while the public health outcome is improved under specific tax system. The ad valorem tax with a specific minimum could achieve greater reduction in consumption than the uniform ad valorem excise system and could also narrow the price gap between the lowest and the upper price bands.

Table 7 The estimates of price and income elasticity of demand for cigarettes in Bangladesh

\begin{tabular}{|c|c|c|c|c|c|c|c|c|}
\hline \multirow[b]{2}{*}{ Factor } & \multicolumn{4}{|c|}{ Price elasticity } & \multicolumn{4}{|c|}{ Income elasticity } \\
\hline & All & Low & Medium & High & All & Low & Medium & High \\
\hline Smoking prevalence: Probit (A) & 0.04 & 0.01 & -0.00 & 0.13 & 0.09 & 0.13 & 0.08 & 0.07 \\
\hline Smoking prevalence: IV Probit (B) & -0.29 & -0.50 & -0.31 & -0.15 & 0.13 & 0.14 & 0.10 & 0.09 \\
\hline Conditional demand: OLS (C) & -0.21 & -0.43 & -0.07 & -0.14 & 0.08 & 0.17 & 0.04 & 0.03 \\
\hline Conditional demand: $2 S L S$ (D) & -0.20 & -0.25 & -0.09 & -0.21 & 0.10 & 0.18 & 0.04 & 0.09 \\
\hline Total $(B+D)$ & -0.49 & -0.75 & -0.40 & -0.36 & 0.23 & 0.33 & 0.15 & 0.18 \\
\hline
\end{tabular}

\footnotetext{
'Low', 'Medium' and 'High' refers to the socioeconomic status of respondents based on housing index. The total price elasticity is obtained by summing the IV probit estimates in row B and the 2SLS estimates in row D.
}

OLS, ordinary least squares; 2 SLS, two-stage least squares. 
Table 8 The simulated impact of increase in cigarette tax on cigarette consumption and revenue in Bangladesh

\begin{tabular}{|c|c|c|c|c|}
\hline Factor & $\begin{array}{l}\text { Baseline: Tiered ad } \\
\text { valorem (low: } 39 \% \text {, } \\
\text { medium: } 56 \% \text {, high: } 59 \% \text {, } \\
\text { premium: } 61 \% \text { of retail } \\
\text { price) }\end{array}$ & $\begin{array}{l}\text { Simulation } A \text { : } \\
\text { uniform ad valorem } \\
\text { at } 61 \% \text { of retail } \\
\text { price }\end{array}$ & $\begin{array}{l}\text { Simulation B: uniform ad valorem } \\
\text { at } 61 \% \text { of retail price with a } \\
\text { specific minimum of } 20 \text { Taka (in } \\
2012 \text { prices) per pack of } 10 \text { sticks }\end{array}$ & $\begin{array}{l}\text { Simulation C: uniform } \\
\text { specific tax of } 22 \text { Taka } \\
\text { (in } 2012 \text { prices) per pack } \\
\text { of } 10 \text { sticks }\end{array}$ \\
\hline $\begin{array}{l}\text { Average excise tax per pack of } 10 \text { sticks } \\
\text { (2012 Taka) }\end{array}$ & 11.89 & 20.90 & 21.18 & 21.57 \\
\hline Average excise tax share in retail price (\%) & $53 \%$ & $61 \%$ & $61 \%$ & $57 \%$ \\
\hline $\begin{array}{l}\text { Average total tax (excise tax and VAT) share } \\
\text { in retail price }(\%)\end{array}$ & $68 \%$ & $76 \%$ & $76 \%$ & $72 \%$ \\
\hline $\begin{array}{l}\text { Average price per pack of } 10 \text { sticks (in } 2012 \\
\text { Taka) }\end{array}$ & 22.46 & 34.26 & 34.65 & 35.67 \\
\hline Percentage change in real price & & $53 \%$ & $54 \%$ & $59 \%$ \\
\hline Number of cigarette smokers (million) & 19.9 & 16.4 & 16.2 & 15.7 \\
\hline $\begin{array}{l}\text { Annual consumption (million packs of } \\
10 \text { sticks) }\end{array}$ & 7603 & 5490 & 5388 & 5125 \\
\hline Percentage change in annual consumption & & $-27.8 \%$ & $-29.1 \%$ & $-32.6 \%$ \\
\hline Revenue (million in 2012 Taka) & 116045 & 154372 & 153497 & 142376 \\
\hline Percentage change in real revenue & & $33.0 \%$ & $32.3 \%$ & $22.7 \%$ \\
\hline
\end{tabular}

\section{DISCUSSION}

The negative price elasticities of smoking prevalence and smoking intensity show that increasing the price of cigarettes in Bangladesh could significantly lower the number of smokers and their daily cigarette consumption. These findings of price elasticity of demand for cigarettes have important implications for public health. For a smoker, positive health benefits are realised to a greater extent for quitting than for reducing consumption. Thus, the proportion of the total price elasticity that is accounted for by elasticity of smoking prevalence is relevant to an understanding of the impact of increasing price on quitting. For high-income countries, the proportion of the total price elasticity that is accounted for by elasticity of smoking prevalence is about $50 \% .^{6}{ }^{20}$ From our analysis of ITC Bangladesh Survey data, the proportion is $0.29 / 0.49=59 \%$. Thus, if taxes were increased on cigarettes in Bangladesh, there would be a greater impact on reducing the prevalence rate (leading to greater gains in enhancing health at the population level) than would be the case in most other countries.

Furthermore, on estimating the cigarette demand function for three groups (low, medium and high socioeconomic status), we observed that the price elasticity of smoking prevalence and smoking intensity were higher the lower the socioeconomic status (SES). The instrumental variable estimates of the price elasticity of smoking prevalence vary from -0.50 (probit) for the low SES population to -0.31 for the medium SES group to -0.15 for the high SES group (table 7). The 2SLS estimates of the price elasticity of smoking intensity vary from -0.25 for low SES group to -0.09 for medium SES group to -0.21 for high SES group (table 7). The total price elasticity is thus measured at -0.75 for the low SES group, -0.40 for the medium SES group and -0.36 for the high SES group. These estimates suggest that poorer people are more price sensitive than the rich and can thus reap greater health gains from increased tax and prices of cigarettes, revealing a behavioural response pattern consistent with the global evidence. ${ }^{6}$

The finding that the overall price elasticity of cigarette demand is less than $1(-0.49)$ implies that a given percentage increase in cigarette price leads to a less than proportionate decrease in cigarette consumption, resulting in greater tobacco expenditure and greater tax revenue for the government. Many would contemplate that this would create a disproportionate burden of tobacco expenditure on the poor. The price elasticity estimates by SES, however, reveal that the price elasticity is higher for low SES, which implies that if prices increased, the poor would cut down cigarette consumption at higher rates than the rich, which would lower the burden of tobacco expenditure and the adverse health consequences on the poor. Ultimately, tax increases that would raise prices would lead to a decrease in the existing inequities in health in Bangladesh.

\section{CONCLUSION}

The analysis of the ITC Bangladesh Survey across two waves affirms analyses conducted in high-income countries as well as in a growing number of low-income and middle-income countries that increasing cigarette tax and price can significantly reduce consumption of cigarettes through reduced smoking prevalence and through lower smoking intensity in continuing smokers. Moreover, in Bangladesh, as in other countries, the impact of increasing price is higher among lower SES people. Whereas in other countries the impact of increasing price on reducing prevalence is about the same as the impact on reducing consumption among smokers, in Bangladesh, the impact on reducing prevalence is about 1.5 times that of reduced consumption, and therefore in Bangladesh the impact of increasing price through taxation would have a considerably greater impact on reducing health harms of tobacco use than in other countries.

We also conclude that raising cigarette taxes and prices can increase government revenue. At the same time, the greater price sensitivity of cigarette consumption among poorer people leads us to conclude that the poor would benefit more from a given cigarette price increase. This would result in a reduction in the inequities of the burden of tobacco consumption that currently exist in Bangladesh, with the negative health and economic impacts of tobacco use being experienced to a much greater extent among the poor. These findings suggest that raising cigarette prices through increased taxation can lead to a win-win-win situation in Bangladesh: it will reduce cigarette consumption, increase tobacco tax revenue and potentially decrease socioeconomic inequities. 


\section{What this paper adds}

- This is the first cigarette demand analysis based on nationally representative individual level survey data collected in Bangladesh.

- Using the price elasticity estimates obtained from the study itself, this paper generates a prediction of reduction in cigarette smoking prevalence and daily use and an increase in government revenue.

- These results may be useful for informed decision making by government in tobacco control through taxation.

Acknowledgements We thank the interviewers at the University of Dhaka who collected data through face-to-face interviews in Bangladesh and the data management staff at the Data Management Center of the University of Waterloo, who processed the data for use.

Contributors NN is the lead author of the paper. UHR conducted the econometric estimation of the price elasticity of cigarette demand. AKMGH ran the simulation to evaluate the impact of tax increase on cigarette consumption and revenue. GTF is the chief investigator of the ITC Project and a coauthor of the paper. IH is the project manager of the ITC Bangladesh Project. SMA is the principal investigator of the ITC Bangladesh Project and a coauthor of the paper.

Funding The ITC Bangladesh Survey was supported by the International Development Research Centre (IDRC Grant 104831-002), Canadian Institutes for Health Research (Operating Grants 57897, 79551 and 115016, and CIHR Strategic Training Program in Tobacco Research: Post-Doctoral Fellowship to the first author), the US National Cancer Institute (R01 CA100362, the Roswell Park Transdisciplinary Tobacco Use Research Center (TTURC; P50 CA111236) and P01 CA138389), Robert Wood Johnson Foundation (045734) and Ontario Institute for Cancer Research (Senior Investigator Award to GTF).

\section{Competing interests None.}

Patient consent Obtained.

Ethics approval The ITC Bangladesh Survey was conducted with the approval of Bangladesh Medical Research Council and the Office of Research Ethics Committee at the University of Waterloo.

Provenance and peer review Not commissioned; externally peer reviewed.
Data sharing statement Additional unpublished data from the study are available to the ITC investigators involved in the Bangladesh project.

\section{REFERENCES}

1 ITC Project. ITC Bangladesh National Report. Waterloo, Ontario, Canada; University of Waterloo; University of Dhaka, Bangladesh, April 2010.

2 World Health Organization. Impact of Tobacco-Related IIInesses in Bangladesh. New Delhi, India: World Health Organization, South East Asia Region, 2007.

3 Bangladesh Population and Housing Census, Bangladesh Bureau of Statistics. 2011.

4 Household Income and Expenditure Survey. Bangladesh Bureau of Statistics. 2010.

5 World Health Organization. Global Adult Tobacco Survey: Bangladesh Report. 2009.

6 IARC Handbooks of Cancer Prevention in Tobacco Control, Volume 14, Effectiveness of Tax and Price Policies for Tobacco Control, International Agency for Research on Cancer. 2011.

7 Ali Z, Rahman A, Rahaman T. An economic analysis of tobacco control in Bangladesh. HNP Discussion Paper. Washington, DC: The World Bank, 2003.

8 Guindon GE, Perucic AM, Boisclair D. Higher tobacco prices and taxes in South-East Asia: an effective tool to eeduce tobacco use, save lives, and generate revenue. HNP Discussion Paper. Washington, DC: The World Bank, 2003.

9 Barkat A, Chowdhury AU, Nargis N, et al. The Economics of Tobacco and Tobacco Taxation in Bangladesh. Paris: International Union Against Tuberculosis and Lung Disease, 2012.

10 Nargis N, Ruthbah UH, Fong GT. Taxation of tobacco products in Bangladesh: findings from the 2009 ITC Bangladesh survey. ITC Project Working Paper Series. Waterloo, Ontario, Canada: University of Waterloo, 2010.

11 Nargis N, Ruthbah UH, Hussain AKMG, et al. Pricing and Taxation of Tobacco Products in Bangladesh: Findings from Wave 1 (2009) and Wave 2 (2010) of the ITC Bangladesh Survey. ITC Project Working Paper Series. Waterloo, Ontario, Canada: University of Waterloo, 2011.

12 World Economic Outlook, International Monetary Organization. 2012.

13 World Health Organization. WHO technical manual on tobacco tax administration. World Health Organization, 2010.

14 Cragg JG. Some statistical models for limited dependent variables with applications to the demand for durable goods. Econometrica 1971;39:829-44.

15 Ramsey JB. Tests for specification errors in classical linear least squares regression analysis. J R Stat Soc B 1969;31:350-71.

16 Deaton $A$. The analysis of household surveys: a microeconomic approach to development policy. Baltimore: John Hopkins University Press, 1997.

17 Stock J, Watson MW. Introduction to econometrics. New York: Prentice Hall, 2003.

18 Wooldridge J. Econometric analysis of cross section and panel data. MIT Press, 2002.

19 Chaloupka FJ, Hu T, Warner KE, et al. The taxation of tobacco products. In: Jha P, Chaloupka FJ, eds. Tobacco control in developing countries. Oxford: Oxford University Press, 2000:237-72.

20 Hu T, Qui-Fang R, Keeler TE, et al. The demand for cigarettes in California and behavioral risk factors. Health Econ 1995:4:7-14. 